\title{
Catalytic Determination of Nanogram Amounts of Vanadium in Natural Water by Flow Injection Analysis
}

\author{
Shigenori Nakano*, Mutsuo Tago* and Takuji KaWashima** \\ *Chemical Institute, Faculty of Education, Tottori University, \\ Koyama-cho, Tottori 680, Japan \\ ** Laboratory of Analytical Chemistry, Department of Chemistry, The University of Tsukuba, \\ Tsukuba, Ibaraki 305, Japan
}

\begin{abstract}
A catalytic-photometric method with a continuous-flow system is presented for the determination of nanogram amounts of vanadium in natural water. It is based on the catalytic effect of vanadium $(V)$ on the oxidative coupling reaction of 4-aminoantipyrine with $\mathrm{N}, \mathrm{N}$-dimethylaniline in the presence of bromate. A higher sensitivity can be attained by using 1,2-dihydroxybenzene-3,5-disulfonic acid (Tiron) as an activator; vanadium(IV, V) at the 0.05 $2.0 \mathrm{ng} \mathrm{ml}^{-1}$ level can be determined at a rate of 30 samples $\mathrm{h}^{-1}$. The method suffers few interferences and can be applied successfully to the determination of vanadium in natural water.
\end{abstract}

Keywords Catalytic analysis, vanadium, spectrophotometry, flow injection analysis, natural water, 4-aminoantipyrine, $N, N$-dimethylaniline

Kinetic methods of analysis based on catalytic reactions are useful in many fields of trace analysis because of their extremely high sensitivity and low limit of detection. Numerous batch methods have been recommended for the catalytic kinetic determination of vanadium. ${ }^{1-10}$ In these batch methods, care is required in the mixing of reagents at regular time intervals in order to obtain highly accurate results. In a flow injection analysis (FIA), the reaction time can easily and precisely be controlled by the flow rate of the solution and the length of reaction coil.

Several procedures for the photometric-catalytic determination of vanadium by FIA have also been described. The catalytic effect on the oxidation of chromotropic acid by bromate allows for the determination of $10-160 \mathrm{ng} \mathrm{ml}^{-1}$ of vanadium. ${ }^{11}$ Hirayama and Unohara ${ }^{12}$ described a procedure for the determination of vanadium up to $80 \mathrm{ng} \mathrm{m}^{-1}$ with the oxidation of Bindschedler's Green by bromate. The reactions of gallic acid ${ }^{13,14}$ and $o$-phenylenediamine ${ }^{15}$ with bromate were used for the catalytic-photometric determination of vanadium.

Recently, the present authors have reported a procedure for the determination of vanadium(IV) and vanadium(V) based on their catalytic effects on the oxidative coupling reaction of 4-aminoantipyrine (4amino-2,3-dimethyl-1-phenyl-5-pyrazolone) with $N, N$ dimethylaniline in the presence of bromate and sulfosalycilic acid (SSA) as an activator. ${ }^{10}$ The absorbance of the product formed during the reaction is measured at a fixed time; $0.1-1.0 \mathrm{ng} \mathrm{ml}^{-1}$ of vanadium can be determined. On this basis, work has now been extended to establish a scheme for the determination of trace amounts of vanadium in water samples. by FIA. In the present work, SSA is replaced by 1,2-dihydroxybenzene-3,5-disulfonic acid (Tiron) as an effective activator; the sensitivity of results have been greatly improved. The conditions for both catalyzed and uncatalyzed reactions were studied in order to adapt the reaction to a flow injection system. A lower determination limit of $0.05 \mathrm{ng} \mathrm{ml}^{-1}$ and a sampling rate of $30 \mathrm{~h}^{-1}$ were achieved in the determination of vanadium in natural water.

\section{Experimental}

\section{Reagents}

All reagents used were of analytical reagent grade. All water used in the experiment was purified using a Millipore Milli- $Q$ water system.

Standard solutions of vanadium(IV) and vanadium(V) $\left(0.5 \mathrm{mgV} \mathrm{ml}^{-1}\right)$ were the same as those described previously. ${ }^{10}$

4-Aminoantipyrine (AA), $N, N$-dimethylaniline (DMA) and potassium bromate solutions were prepared in a manner similar to that described earlier ${ }^{10}$, though $4.0 \times 10^{-3} \mathrm{M}$ AA, $3.0 \times 10^{-2} \mathrm{M}$ DMA and $8.0 \times 10^{-2} \mathrm{M}$ bromate solutions were used. An aqueous $0.1 \mathrm{M}$ Tiron solution was prepared from DOJINDO Laboratories, 


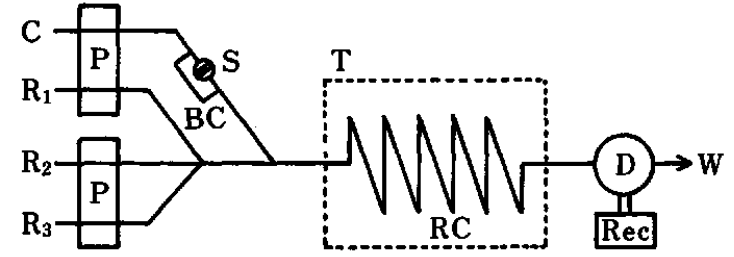

Fig. I Flow diagram of FIA for the catalytic determination of vanadium. $C$, carrier solution $(0.1 \mathrm{M} \mathrm{HCl}) ; R_{1}, A A$ $\left(4.0 \times 10^{-3} \mathrm{M}\right) / \mathrm{DMA}\left(3.0 \times 10^{-2} \mathrm{M}\right) /$ Tiron $(0.1 \mathrm{M})$ solution; $\mathbf{R}_{2}$, potassium bromate solution $\left(8.0 \times 10^{-2} \mathrm{M}\right) ; \mathbf{R}_{\mathbf{3}}$, buffer solution $\left(0.15 \mathrm{M}\right.$ sodium formate $\left./ \mathrm{NH}_{3} / \mathrm{HCl}\right)$; $\mathrm{P}$, pump $\left(0.8 \mathrm{ml} \mathrm{min}^{-1}\right) ; \mathrm{S}$, sample injector (sample volume $200 \mu \mathrm{l}$ ); BC, bypass coil (3 m long, $0.25 \mathrm{~mm}$ i.d.); RC, reaction coil ( $10 \mathrm{~m}$ long, $0.5 \mathrm{~mm}$ i.d.); $\mathrm{T}$, thermostated bath $\left(55^{\circ} \mathrm{C}\right), \mathrm{D}$, spectrophotometer $(555 \mathrm{~nm})$; Rec, recorder; W, waste (pH 2.6-2.7).

Japan, without further purification.

\section{Apparatus}

A flow diagram for the determination of vana$\operatorname{dium}(\mathrm{IV}, \mathrm{V})$ and experimental parameters are shown in Fig. 1. Two double plunger pumps (Tokyo Rika PS $3.2 \mathrm{~W}$ ) were used; sample solutions were injected by a six-way injection valve (Tokyo Rika VMU-6) into the carrier stream. The flow lines were made from Teflon tubing $(0.5 \mathrm{~mm}$ i.d.) and connectors. A Japan Spectroscopic Co. UVIDEC-320 spectrophotometer equipped

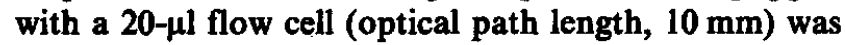
used and connected to a Hitachi 056 recorder. A Toa Denpa Model HM-6A pH meter and a thermostated bath (Toyo LH-1000) were also used.

\section{Procedure}

In the flow system (Fig. 1), a $0.1 \mathrm{M}$ hydrochloric acid carrier solution (C) was pumped at a flow rate of $0.8 \mathrm{ml} \mathrm{min}^{-1}$. An aqueous solution containing AA, DMA and Tiron in a reservoir $R_{1}$ was supplied to the manifold. The solutions of bromate and formate buffer in reservoirs $R_{2}$ and $R_{3}$, respectively, were also supplied. A 200- $\mu$ l aliquot of the sample solution was injected by a loop-injection valve into the carrier stream, which was then merged with AA, DMA, Tiron, bromate and buffer streams at $0.8 \mathrm{ml} \mathrm{min}$. The catalytic action of vanadium(IV, V) on the oxidative coupling reaction proceeded in the reaction coil $(10 \mathrm{~m}$ long, $0.5 \mathrm{~mm}$ i.d.) which was submerged in a thermostated bath of $55 \pm 0.1^{\circ} \mathrm{C}$. The absorbance of the dye formed was monitored continuously at $555 \mathrm{~nm}$.

\section{Results and Discussion}

The oxidative coupling reaction of AA with DMA by bromate is slow, but can be catalyzed by vanadium(IV) and vanadium(V); their catalytic effects could

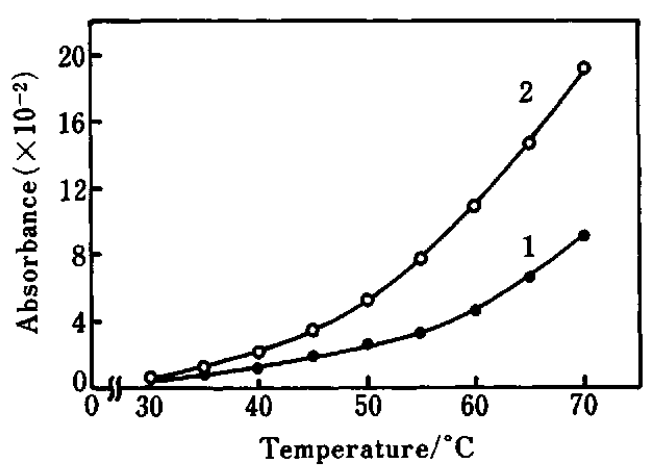

Fig. 2 Effect of temperature on color development. 1, base line; $2,2.0 \mathrm{ng} \mathrm{ml}^{-1}$ of vanadium(V). Other conditions as in Fig. 1.

be activated by Tiron and SSA, respectively. The reaction product, $N$-(2,3-dimethyl-1-phenyl-5-pyrazolone)$N^{\prime}, N^{\prime}$-dimethylamino-p-benzoquinone diiminonium ion, exhibits an absorption maximum at $555 \mathrm{~nm}$, as described previously. ${ }^{10}$

\section{Optimum conditions for FIA}

In the application of a catalytic reaction to FIA, the peak height obviously depends on the flow rate and the reaction coil length. The lower flow rates gave higher peaks for the catalyzed and uncatalyzed reactions. A flow rate of $0.8 \mathrm{ml} \mathrm{min}^{-1}$ in each stream was selected, taking into account the sensitivity and the sampling frequency. By lengthening the reaction coil from 2 to $14 \mathrm{~m}$, the peak height increased. A $10-\mathrm{m}$ coil was chosen after considering of the sensitivity and the base line stability.

The peak height increased with increasing sample volume, but almost reached its maximum above $200 \mu \mathrm{l}$; this volume was, therefore, recommended.

\section{Effect of reaction variables}

The effect of temperature on both catalyzed and uncatalyzed reactions was examined over the range $30-$ $70^{\circ} \mathrm{C}$. An increase in the temperature increased the peak height for both reactions, as shown in Fig. 2. As expected, this effect is much pronounced for a catalyzed reaction. A temperature of $55^{\circ} \mathrm{C}$ was selected in the procedure for the sake of high sensitivity and base line stability.

The effect of $\mathrm{pH}$ on the both reactions was studied by adding different amounts of 0.1 and $1.0 \mathrm{M}$ hydrochloric acid in the presence of Tiron $(0.1 \mathrm{M})$ or SSA $(0.3 \mathrm{M})$. As can be seen in Fig. 3, the rate of an uncatalyzed reaction is faster at lower $\mathrm{pH}$. An optimum $\mathrm{pH}$ range for the catalyzed reactions was found to be 2.6-2.7. The effect of buffers was also examined, since the rate of a catalyzed reaction sometimes depended on the buffer used to control the reaction $\mathrm{pH}$. The buffers examined include tartrate, citrate and formate. In the presence of tartrate or citrate, the rate of a catalyzed 


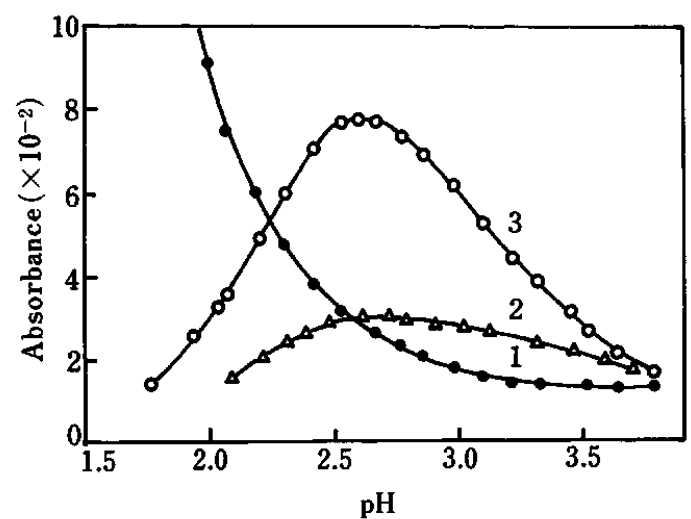

Fig. 3 Effect of $\mathrm{pH}$ on color development in the presence of Tiron $(0.1 \mathrm{M}, \mathrm{O})$ or SSA $(0.3 \mathrm{M}, \Delta)$. 1, base line; 2, 3, $2.0 \mathrm{ng} \mathrm{m}^{-1}$ of vanadium(V). Other conditions as in Fig. 1.

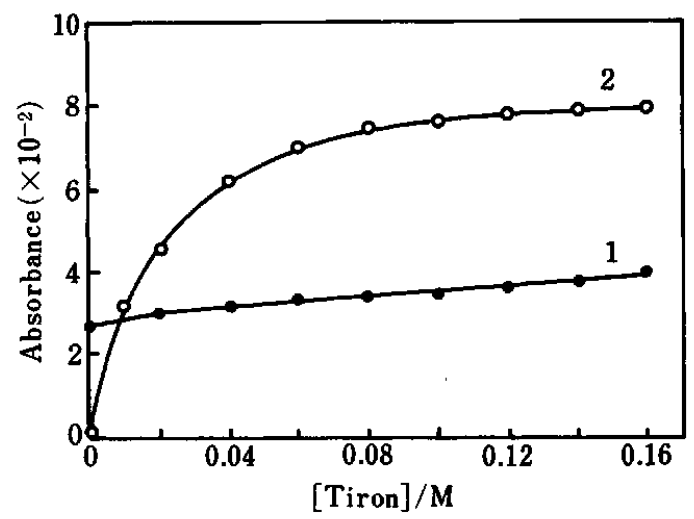

Fig. 4 Effect of Tiron concentration. 1, base line; 2, 2.0 $\mathrm{ng}$ $\mathrm{ml}^{-1}$ of vanadium(V). Other conditions as in Fig. 1 .

reaction was retarded; in the presence of formate, however, the reaction rate was not influenced $(0.15 \mathrm{M}$ of a formate solution was used).

The effect of AA and DMA concentrations was examined. The higher were the concentrations of AA and DMA, the higher were the absorbance for catalyzed reactions. The height of the base line slightly increased with increasing concentrations of $\mathrm{AA}$ and DMA. The concentrations of AA and DMA were selected to be $4.0 \times 10^{-3} \mathrm{M}$ and $3.0 \times 10^{-2} \mathrm{M}$, respectively.

The effect of bromate concentration over the range $0-0.15 \mathrm{M}$ on the catalyzed and uncatalyzed reactions was studied. Both reactions proceeded faster with increasing bromate concentration. A $8.0 \times 10^{-2} \mathrm{M}$ bromate concentration was chosen.

At present, the most promising possibility for a further increase in the sensitivity of the catalytic methods seems to be through the used of activators. ${ }^{16,17}$ Hwang et al. ${ }^{15}$ have reported that Tiron acts as an activator for vanadium(V). In the present study, the activating effect of Tiron and SSA was examined for a catalyzed reaction of vanadium(V). As can be seen in

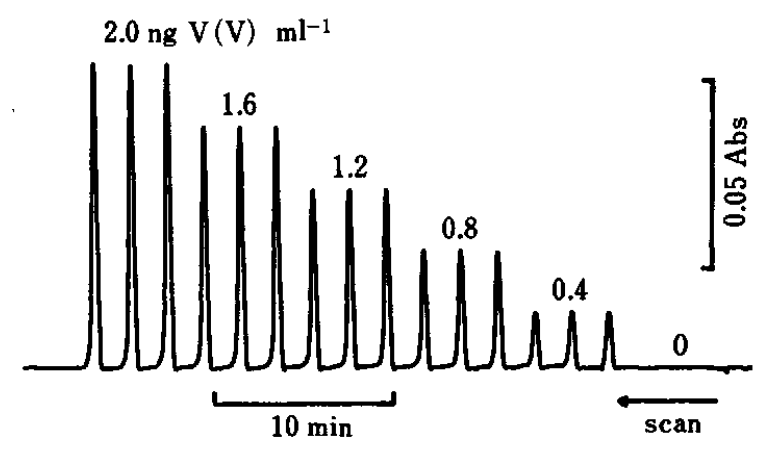

Fig. 5 Flow signals for vanadium(V). Conditions as in Fig. 1.

Table 1 Effect of foreign ions on the determination of 1.0 $\mathrm{ng} \mathrm{m} \mathbf{~}^{-1}$ of vanadium(V)

\begin{tabular}{|c|c|}
\hline $\begin{array}{l}\text { Tolerance } \\
\text { limit/ng ml-1 }\end{array}$ & Ion added \\
\hline 100000 & $\begin{array}{l}\mathrm{Al}(\mathrm{III}), \mathrm{As}(\mathrm{III}), \mathrm{As}(\mathrm{V}), \mathrm{Ba}(\mathrm{II}), \mathrm{Ca}(\mathrm{II}), \mathrm{Cd}(\mathrm{II}) \text {, } \\
\mathrm{Co}(\mathrm{II}), \mathrm{Hg}(\mathrm{II}), \mathrm{K}(\mathrm{I}), \mathrm{Mg}(\mathrm{II}), \mathrm{Na}(\mathrm{I}), \mathrm{Ni}(\mathrm{II}), \\
\mathrm{Zn}(\mathrm{II}), \mathrm{Cl}^{-}, \mathrm{CO}_{3}{ }^{2-}, \mathrm{NO}_{3}{ }^{-}, \mathrm{PO}_{4}{ }^{3-}, \mathrm{SO}_{4}{ }^{2-}\end{array}$ \\
\hline 10000 & $\begin{array}{l}\mathrm{Ce}(\mathrm{III}), \mathrm{Cr}(\mathrm{III}), \mathrm{Mn}(\mathrm{II}), \mathrm{Pb}(\mathrm{II}), \mathrm{Se}(\mathrm{IV}) \\
\mathrm{W}(\mathrm{VI}), \mathrm{BO}_{3}{ }^{3-}, \mathrm{Br}^{-}, \mathrm{ClO}_{4}^{-}, \mathrm{F}^{-}, \mathrm{I}^{-}\end{array}$ \\
\hline 1000 & $\mathrm{Bi}(\mathrm{III}), \mathrm{Ce}(\mathrm{IV}), \mathrm{Mo}(\mathrm{VI}), \mathrm{Sn}(\mathrm{IV}), \mathrm{NO}_{2}^{-}$ \\
\hline 100 & $\mathrm{Cr}(\mathrm{VI}), \mathrm{Cu}(\mathrm{II}), \mathrm{Fe}(\mathrm{II}), \mathrm{Fe}(\mathrm{III}), \mathrm{Sn}(\mathrm{II})$ \\
\hline
\end{tabular}

Fig. 3, the activating effect of Tiron in greater than that of SSA. The effect of Tiron concentration is shown in Fig. 4; the peak height increased with increasing Tiron concentration, though above $0.08 \mathrm{M}$ no significant increase was observed. Therefore, a Tiron concentration of $0.1 \mathrm{M}$ was selected for the procedure.

\section{Calibration graph}

The flow system (Fig. 1) was used for preparing calibration graphs. Typical signals for vanadium(V) are shown in Fig. 5. The calibration graphs are linear over the concentration range $0.05-2.0 \mathrm{ng} \mathrm{m}^{-1}$ of vana$\operatorname{dium}(\mathrm{V})$. Curves for vanadium(IV) were also prepared and were almost identical to those for vanadium(V), presumably because vanadium(IV) is oxidized to vana$\operatorname{dium}(\mathrm{V})$ by bromate. Thus, the proposed method can be used to determine the total vanadium. The detection limit of the method for a signal-to-noise ratio of 3 is $20 \mathrm{pg} \mathrm{ml}^{-1}$. The precision of the present method was tested by injecting 10 samples and recording the peak absorbances. Relative standard deviations are $\mathbf{0 . 8}$ and $0.5 \%$ for 1.0 and $2.0 \mathrm{ng} \mathrm{ml}^{-1}$ of vanadium(V), respectively.

\section{Interferences}

The effect of foreign ions on the determination of $1.0 \mathrm{ng} \mathrm{ml}^{-1}$ of vanadium(V) was studied. The tolerance limits for foreign ions are summarized in Table 1; a 5\% error was considered to be tolerable. As can be seen, 
Table 2 Determination of vanadium in river and lake water

\begin{tabular}{lccc}
\hline \multirow{2}{*}{ Sample $^{\mathrm{a}}$} & \multicolumn{3}{c}{ Vanadium found $/ \mathrm{ng} \mathrm{ml}^{-1}$} \\
\cline { 2 - 4 } & $\begin{array}{c}\text { Proposed method } \\
(\text { (I) }\end{array}$ & Batch method \\
& & & \\
\hline River water & & \\
Gamou-gawa & $0.3_{2} \pm 0.0_{1}$ & $0.3_{2} \pm 0.0_{1}$ & $0.3_{4} \pm 0.0_{4}$ \\
Kyufukuro-gawa & $0.2_{1} \pm 0.0_{1}$ & $0.2_{1} \pm 0.0_{1}$ & $0.2_{3} \pm 0.0_{1}$ \\
Sendai-gawa & $0.3_{6} \pm 0.0_{1}$ & $0.3_{7} \pm 0.0_{1}$ & $0.3_{7} \pm 0.0_{2}$ \\
Tenjin-gawa & $0.3_{2} \pm 0.0_{1}$ & $0.3_{3} \pm 0.0_{3}$ & $0.3_{3} \pm 0.0_{2}$ \\
Lake water & & & \\
Koyama-ike & $0.1_{0} \pm 0.0_{1}$ & $0.1_{2} \pm 0.0_{1}$ & $0.1_{2} \pm 0.0_{2}$ \\
Togo-ike & $0.2_{6} \pm 0.0_{1}$ & $0.2_{7} \pm 0.0_{1}$ & $0.2_{7} \pm 0.0_{2}$ \\
\hline
\end{tabular}

a. Collected in Tottori Prefecture, Japan.

b. Corrected for addition $(n=3)$.

c. Calibration curve method.

d. Standard addition method.

most of the foreign ions showed no effect on the determination of vanadium( $(V)$, even when present in amounts of 1000-fold excess. Chromium(VI), copper(II), iron(II, III) showed positive interferences and tin(II) showed negative one. However, these ions up to 100-fold amounts to vanadium(V) did not interfere. The selectivity of the present method was better than that of the batch method. ${ }^{10}$

\section{Application to water samples}

The applicability of the proposed method was evaluated by analyzing both river and lake water. After a pretreatment ${ }^{10}$, the determination of vanadium was performed by FIA; in all cases calibration curves and standard addition methods were applied. The obtained results are given in Table 2 . The results obtained by the proposed method were compared with those obtained by the batch method.10 Both results are in good agreement. The sensitivity and the accuracy of the method are satisfactory and the proposed method is useful for the determination of $0.1-2 \mathrm{ng} \mathrm{ml}^{-1}$ vanadium in natural water, such as river or lake water.

Financial support from the Ministry of Education, Science and Culture (No. 62470030 and 62540438) is gratefully acknowledged.

\section{References}

1. T. Yamane and T. Fukasawa, Bunseki Kagaku, 25, 454 (1976).

2. K. Hirayama and N. Unohara, Bunseki Kagaku, 29, 733 (1980).

3. T. Kawashima, S. Karasumaru, M. Hashimoto and S. Nakano, Nippon Kagaku Kaishi, $1981,175$.

4. S. Nakano, E. Kasahara, M. Tanaka and T. Kawashima, Chem. Lett., $1981,597$.

5. M. Otto, G. Schöbel and G. Werner, Anal. Chim. Acta, 147, 287 (1983).

6. Q. Weiguo, Anal. Chem., 55, 2043 (1983).

7. A. Sevillano-Cabeza, J. Medina-Escriche and F. BoschReig, Analyst [London], 109, 1559 (1984).

8. C. G. Papadopoulos and G. S. Vasilikiotis, Mikrochim. Acta [Wien], 1985 III, 31.

9. T. Fukasawa, S. Kawakubo and T. Yamanouchi, Anal. Chim. Acta, 171, 325 (1985).

10. S. Nakano, C. Yamada, M. Sakai and T. Kawashima, Anal. Sci., 2, 61 (1986).

11. T. Yamane and T. Fukasawa, Anal. Chim. Acta, 119, 389 (1980).

12. K. Hirayama and N. Unohara, Nippon Kagaku Kaishi, $1981,98$.

13. T. Fukasawa, S. Kawakubo, T. Okabe and A. Mizuike, Bronseki Kagaku, 33, 609 (1984).

14. T. Fukasawa, S. Kawakubo and A. Unno, Anal. Chim. Acta, 183, 269 (1986).

15. J. M. Hwang, J. C. Tsung and Y. M. Chen, J. Chin. Chem. Soc. [Taipei], 32, 405 (1985).

16. P. R. Bontchev, Talanta, 19, 675 (1972).

17. D. P. Nikolalis and T. P. Hadjiioannu, Rev. Anal. Chem., 4, 81 (1979). 